Oct 2016, Volume 1, Issue 3 (68-70)

\title{
Cardiac Failure Secondary to Hypocalcemia
}

\author{
Mohammad Hasan Namazi ${ }^{1}$, Isa Khaheshi ${ }^{1,{ }^{*}}$, Mahsa \\ Charkhkar $^{2}$, Shooka Esmaeeli ${ }^{3}$, Habib Heybar ${ }^{4}$
}

${ }^{1}$ Cardiovascular Research Center, Shahid Beheshti University of Medical Sciences, Tehran, Iran

${ }^{2}$ Cardiovascular Research Center, Modarres Hospital, Shahid Beheshti University of Medical Sciences, Tehran, Iran

${ }^{3}$ Students, Scientific Research Center (SSRC), Tehran University of Medical

Sciences, Tehran, Iran

${ }^{4}$ Cardiovascular Research Center, Ahvaz Jundishapur University of Medical

Sciences, Ahvaz, Iran

* Corresponding author: Cardiovascular Research Center, Modarres Hospital, Shahid Beheshti University of Medical Sciences, Kaj Square, Saadatabad, Tehran, Iran. Tel:

DOI: $10.21859 / \mathrm{ijcp}-010304$ +98-2122074088, E-mail: isa_khaheshi@yahoo.com

Submited: 09.12.2016

Accepted: 09.28.2016

Keywords:

Heart Failure

Hypocalcemia

Hypoparathyroidism

(C) 2016. International Journal of

Cardiovascular Practice.

\begin{abstract}
Hypocalcemic cardiomyopathy due to hypoparathyroidism is a very atypical and rare circumstance, which is usually intractable to conventional therapy for cardiac failure, but responds satisfactorily to restoration of normocalcemia.

We describe a young woman who developed clinical signs of hypocalcemia due to hypoparathyroidism, reduced left ventricular ejection fraction and polymorphic ventricular tachycardia as consequences of hypocalcemia.

This case underscores the importance of biochemical abnormalities like hypocalcemia as a rare cause of secondary cardiomyopathy and emphasizes on the need for effective and immediate treatment of hypocalcemia and its related causes.
\end{abstract}

\section{INTRODUCTION}

Dilated cardiomyopathy could be primary or secondary. Even if some causes are familiar, such as toxic agents (alcohol or drugs of chemotherapy) or viral and bacterial infections, biochemical abnormalities are much less common [1]. Hypocalcemia diminishes myocardial contractility and results in left ventricular systolic dysfunction [2].

In this paper, we report a case of heart failure with hypocalcemia and primary hypoparathyroidism which was treated with vitamin $\mathrm{D}$ and calcium supplement.

\section{CASE PRESENTATION}

A 21-year-old female was admitted to our emergency department due to worsening dyspnea (NYHA class III) for seven days. Her past medical history was significant for primary hypoparathyroidism from six years ago, but she discontinued her regular medication (oral calcium and vitamin D) from three months. Moreover, she complained about numbness of both hands and feet for two months.

On physical examination, blood pressure was $100 / 65 \mathrm{mmHg}$, heart rate was 78 beats per minute, respiratory rate was 16 breaths per minute, and body temperature was $36.8^{\circ} \mathrm{C}$. Chvostek's and Trousseau's signs were positive. On auscultation of the chest, there were coarse fine rales on the base of both lung fields, and grade III systolic murmur on apex and left sternal border were heard. The reminder of her physical examination was unremarkable.
Her electrocardiogram (ECG) showed normal sinus rhythm with $\mathrm{T}$ wave inversion in the precordial leads and prolonged QTc interval $(520 \mathrm{msec})$. The transthoracic echocardiography demonstrated global hypokinesia of the LV with $13 \%$ left ventricular ejection fraction $(\mathrm{EF})$, moderate diastolic dysfunction and mild mitral regurgitation (Fig 1). Chest radiography revealed cardiomegaly. Perfusion stress test revealed no signs of ischemia.

Laboratory studies revealed the following: magnesium 1.5 $\mathrm{mg} / \mathrm{dL}$ (reference range: 1.6-3.0 mg/dL), albumin $4.2 \mathrm{~g} /$ $\mathrm{dL}$ (reference range: $3-5.5 \mathrm{mg} / \mathrm{dL}$ ), corrected calcium $7 \mathrm{mg} /$ $\mathrm{dL}$ (reference range: $8.6-10 \mathrm{mg} / \mathrm{dL}$ ), phosphate $10.1 \mathrm{mg} / \mathrm{dL}$ (reference range: $2.5-5 \mathrm{mg} / \mathrm{dL}$ ), and intact parathyroid hormone (PTH-I) $6 \mathrm{pg} / \mathrm{mL}$ (reference range: $15-65 \mathrm{pg} / \mathrm{mL}$ ). CK-MB, cardiac troponin I, complete blood count, blood urea nitrogen (BUN), serum creatinine, blood glucose, $\mathrm{Na}+$, $\mathrm{K}+$, alanine aminotransferase (SGOT), aspartate aminotransferase (SGPT), alkaline phosphatase, bilirubin, T3, T4 and TSH were within normal ranges. Viral markers and full panel of rheumatology studies for autoimmune antibodies were all negative.

At the first night of her admission, she developed abnormal tonic movement, loss of consciousness and episode of polymorphic ventricular tachycardia (Fig 2), which was controlled with asynchronized $200 \mathrm{~J}$ shock. Treatment initiated with administration of furosemide, captopril, digitalis and spironolactone. In addition, calcium, magnesium and vitamin $\mathrm{D}$ were added to her drug regimen. 
Following normalization of her calcium level, she was discharged after five days under the treatment of oral calcium, vitamin $\mathrm{D}_{3}$, furosemide, carvedilol and captopril. Her ejection fraction at the time of discharge was $36 \%$. She was planned for follow-up transthoracic echocardiography for evaluation of the cardiac function as well as for close observation of cardiology and endocrinology clinics.

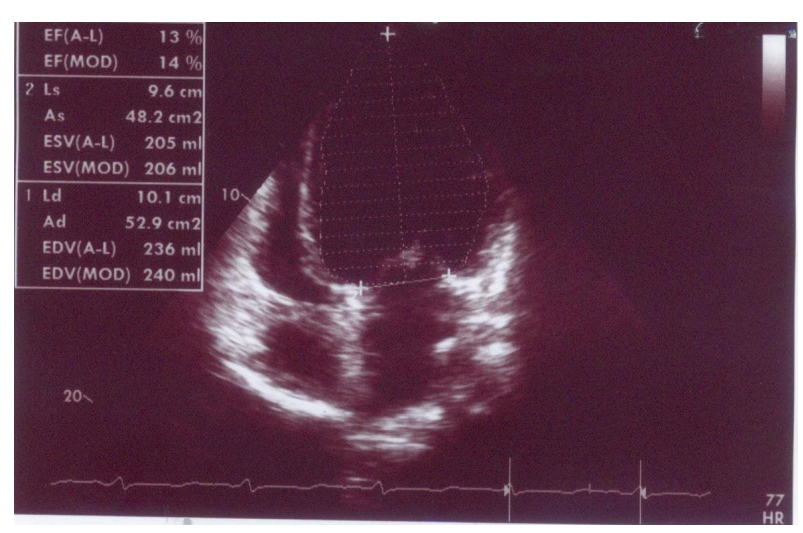

Figure 1: Transthoracic Echocardiography Demonstrated Global Hypokinesia of the LV with 13\% of Left Ventricular Ejection Fraction, Which Was Measured by Biplane Simpson Method

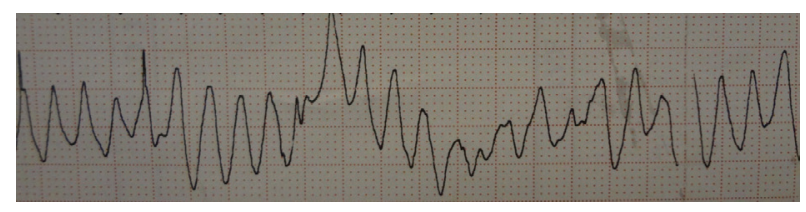

Figure 2: Polymorphic Ventricular Tachycardia Developed at the Night of the Admission

\section{DISCUSSION}

Hypocalcemia is a very unusual reversible cause of dilated cardiomyopathy, which can involve one or both ventricles. Hypocalcemia diminishes myocardial contractility, but the prevalence of congestive heart failure due to hypocalcemia is uncommon $[2,3]$. Hypocalcemic cardiomyopathy due to hypoparathyroidism is a very atypical circumstance which is usually intractable to conventional therapy for cardiac failure, but responds satisfactorily to restoration of normocalcemia $[4,5]$.

Ionized calcium has an essential task for regulating myocardial contraction. During the cardiac action potential, ionized calcium enters the cells through depolarization-activated calcium channels. The entered ionized calcium elicits calcium release from the sarcoplasmic reticulum. $\mathrm{Ca}^{2+}$ binds to myofilaments proteins such as troponin $\mathrm{C}$, commencing contraction of myocardium $[6,7]$.

Hypocalcemia results in not only heart failure, but also ST segment changes in ECG, which mimic acute myocardial ischemia and infarction; it may lead to life threatening cardiac arrhythmia like polymorphic ventricular tachycardia [8]. The hemodynamic and echocardiographic improvement of hypocalcemic cardiomyopathy could not be attained by usual medical treatments of heart failure [9].

The roles of calcium and vitamin $\mathrm{D}$ are pivotal in the treatment of hypocalcemic cardiomyopathy; but, it has been also emphasized on the impending role of parathyroid hormone (PTH) in preserving myocardial contractility [10]. Correction of serum level of calcium was not adequate for restitution of myocardial function. Rather, re-establishment of intracellular calcium level is thought to be more essential to returning myocardial function. It would take several months to normalized tissue calcium level [11]. Although cardiac function usually returns to normal status, there are some reports of persistent systolic dysfunction after vitamin $\mathrm{D}$-calcium supplementation $[12,13]$. There was no obvious cause for dilated cardiomyopathy in our case. Hypocalcemia was the lone probable cause, according to the pervious unusual case reports.

This case underscores the importance of biochemical abnormalities like hypocalcemia as a rare cause of secondary cardiomyopathy and emphasizes on the need for effective and immediate treatment of hypocalcemia and its related causes.

\section{ACKNOWLEDGMENTS}

There is no acknowledgment for the present study.

\section{CONFLICTS OF INTEREST}

Authors declare that there is no conflict of interest for the present study.

\section{REFERENCES}

1. Charniot JC, Alexeeva A, Laurent S, Zerhouni K, Barthelemy B, Cohen $\mathrm{R}$, et al. [Reversible hypokinetic cardiomyopathy revealing severe hypocalcemia]. Arch Mal Coeur Vaiss. 2001;94(7):747-50. PMID: 11494634

2. Avsar A, Dogan A, Tavli T. A rare cause of reversible dilated cardiomyopathy: hypocalcemia. Echocardiography. 2004;21(7):609-12. DOI: $10.1111 /$ j.0742-2822.2004.03149.x PMID: 15488088

3. Connor TB, Rosen BL, Blaustein MP, Applefeld MM, Doyle LA. Hypocalcemia precipitating congestive heart failure. N Engl J Med. 1982;307(14):869-72. DOI: 10.1056/NEJM198209303071407 PMID: 7110262

4. Altunbas H, Balci MK, Yazicioglu G, Semiz E, Ozbilim G, Karayalcin U. Hypocalcemic cardiomyopathy due to untreated hypoparathyroidism. Horm Res. 2003;59(4):201-4. DOI: 69324 PMID: $\underline{12649575}$

5. Ozerkan F, Gungor H, Zoghi M, Nalbantgil S. [Cardiac failure secondary to idiopathic hypoparathyroidism: a case report]. Turk Kardiyol Dern Ars. 2009;37(1):53-6. PMID: 19225256

6. Bers DM. Cardiac excitation-contraction coupling. Nature. 2002;415(6868):198-205. DOI: 10.1038/415198a PMID: 11805843

7. Sung JK, Kim JY, Ryu DW, Lee JW, Youn YJ, Yoo BS, et al. A case of hypocalcemia-induced dilated cardiomyopathy. J Cardiovasc Ultrasound. 2010;18(1):25-7. DOI: 10.4250/jcu.2010.18.1.25 PMID: 20661333

8. Rallidis LS, Gregoropoulos PP, Papasteriadis EG. A case of severe hypocalcaemia mimicking myocardial infarction. International Journal of Cardiology. 1997;61(1):89-91. DOI: 10.1016/s01675273(97)00124-1

9. Avramides DA, Ionitsa SS, Panou FK, Ramos AN, Koutmos ST, Zacharoulis AA. Dilated cardiomyopathy and hypoparathyroidism: complete recovery after hypocalcemia correction. Hellenic J Cardiol. 2003;44:150-4.

10. Ballane GT, Sfeir JG, Dakik HA, Brown EM, El-Hajj Fuleihan G. Use of recombinant human parathyroid hormone in hypocalcemic cardiomyopathy. Eur J Endocrinol. 2012;166(6):1113-20. DOI: 
10.1530/EJE-11-1094 PMID: 22430263

11. Breslau NA, Pak CYC. Hypoparathyroidism. Metabolism. 1979;28(12):1261-76. DOI: 10.1016/0026-0495(79)90141-0

12. Chraibi S, Drighl A, Nafidi S, Zahraoui M, Tahiri A, Chraibi N. [Hypocalcemic dilated cardiomyopathy: rare cause of heart failure]. Ann
Med Interne (Paris). 2001;152(7):483-5. PMID: 11965090

13. Lam J, Maragano P, Lepez B, Vasquez L. [Hypocalcemic cardiomyopathy secondary to hypoparathyroidism after a thyroidectomy: report of one case]. Rev Med Chil. 2007;135(3):359-64. DOI: S0034-98872007000300011 PMID: 17505582 